\title{
OESOPHAGUS
}

\section{Risk of oesophageal cancer in Barrett's oesophagus and gastro-oesophageal reflux}

\author{
M Solaymani-Dodaran, R F A Logan, J West, T Card, C Coupland
}

Gut 2004;53:1070-1074. doi: 10.1136/gut.2003.028076

See end of article for authors' affiliations

....................

Correspondence to: Dr M Solaymani-Dodaran, University of Nottingham, Division of Epidemiology and Public Health,

Queen's Medical Centre,

Nottingham NG7 2UH,

UK; mcxms1@

nottingham.ac.uk

Accepted for publication 23 December 2003

\begin{abstract}
Background and aims: While patients with Barrett's oesophagus develop oesophageal adenocarcinoma more frequently than the general population, it has controversially been suggested that gastrooesophageal reflux (GORD) itself is a more important determinant of risk. In order to assess the validity of this suggestion, we examined the risk of oesophageal cancer in patients with Barrett's and with GORD compared with the general population in a community based cohort study.

Methods: Cohorts of patients with Barrett's $(n=1677)$, oesophagitis $(n=6392)$, and simple reflux $(n=6328)$, and a reference cohort $(n=13416)$ were selected from the General Practice Research Database. The last three cohorts were matched to the Barrett's cohort by general practitioner practice, age, and sex. Cox's regression analysis was used to calculate relative risks for oesophageal cancer. Standardised incidence ratio methodology was used to estimate the relative risks for oesophageal adenocarcinoma.

Results: A total of 137 oesophageal cancers were identified, of which 94 prevalent cases were excluded. The hazard ratios for oesophageal cancer were $10.6(5.1-22.0), 2.2(0.9-5.2)$, and $1.7(0.7-4.5)$ in the Barrett's, oesophagitis, and reflux cohorts compared with the reference cohort, respectively. The corresponding relative risks for oesophageal adenocarcinoma were 29.8 (9.6-106), 4.5 (1.04-19.6), and $3.1(0.6-14.2)$.

Conclusion: Barrett's oesophagus increases the risk of oesophageal cancer approximately 10 times and oesophageal adenocarcinoma approximately 30 times compared with the general population. There is only a modestly increased risk of oesophageal cancer in patients with reflux who have no record of Barrett's oesophagus. Our findings therefore do not support the suggestion that gastro-oesophageal reflux disease itself predisposes to cancer.
\end{abstract}

$\mathrm{B}$ arrett's oesophagus is recognised as a premalignant condition, with the incidence of adenocarcinoma in those with Barrett's being much higher than in the general population. ${ }^{1-26}$ There have been at least 27 cohort studies with relative risk estimates varying from as low as 30 fold ${ }^{27}$ to more than 500 -fold. ${ }^{18}$ Most have been based on relatively small numbers of cancers developing (maximum eight cancers) and of years of follow up. Most were also unable to adjust for age and sex differences and lacked an internal control group necessitating comparisons with population incidence values. A recent review of the risk of adenocarcinoma in Barrett's oesophagus ${ }^{28}$ concluded that publication bias may have resulted in an overestimate of the cancer risk.

Moreover, the findings of a Swedish case control study ${ }^{29}$ have raised questions as to the critical role of Barrett's oesophagus. In $38 \%$ of oesophageal adenocarcinoma cases in this study, Barrett's oesophagus could not be identified, and yet the strength of the association between reflux symptoms and cancer was as strong in these cases as it was in those cases where Barrett's could be identified. Hence Lagergren et al hypothesised that gastro-oesophageal reflux disease (GORD) rather than Barrett's oesophagus may be the crucial factor in the aetiology of oesophageal adenocarcinoma. To date, this hypothesis has not been tested.

We have therefore conducted a large cohort study using prospectively gathered data from the General Practice Research Database (GPRD) to examine whether GORD confers the same risk of oesophageal cancer as Barrett's oesophagus.

\section{METHODS}

We selected study subjects from GPRD, the largest electronic database of longitudinal primary care records in the world, with over 40 million patient years of follow up data. The database, established in 1987, contains the medical history of patients, as recorded by their general practitioner at every visit. Information transfers automatically from the desktop computer of the general practitioner to the database and includes all signs, symptoms, prescribed drugs, hospital letters, and communications with other health institutes. The data from GPRD practices are audited regularly and must contain at least $95 \%$ of all morbidity and prescribing information for the participating practice before being regarded as providing "up to standard" data. ${ }^{30}$

All patients having a record of "Barrett's oesophagus", "Barrett's ulcer", or "columnar lined oesophagus" in the GPRD between 1987 and 2001 were included in the Barrett's cohort. Three further cohorts were selected for comparison. The first (the oesophagitis cohort) consisted of those people who had a record of reflux related oesophagitis, excluding chemical, acute, gangrenous, phlegmonous, and postoperative oesophagitis but without any record of Barrett's. The second cohort (the simple reflux cohort) contained subjects who had a record of gastro-oesophageal reflux and no record of any antireflux operations, Barrett's oesophagus, or oesophagitis. The third cohort (the standard reference cohort) was selected without restriction other than not

Abbreviations: GPRD, General Practice Research Database; GORD, gastro-oesophageal reflux disease; SIR, standardised incidence ratio 
Table 1 Characteristics of the study cohorts

\begin{tabular}{|c|c|c|c|c|c|c|c|c|}
\hline & \multicolumn{4}{|l|}{ Men } & \multicolumn{4}{|l|}{ Women } \\
\hline & Barrett's & Oesophagitis & Reflux & $\begin{array}{l}\text { Standard } \\
\text { ref }\end{array}$ & Barrett's & Oesophagitis & Reflux & $\begin{array}{l}\text { Standard } \\
\text { ref }\end{array}$ \\
\hline No of subjects $(n=27813)$ & 1033 & 3897 & 3828 & 8264 & 644 & 2495 & 2500 & 5152 \\
\hline (\% in each cohort) & $62 \%$ & $61 \%$ & $60 \%$ & $62 \%$ & $38 \%$ & $39 \%$ & $40 \%$ & $38 \%$ \\
\hline Mean age $(y)$ & 61.0 & 61.3 & 61.1 & 61.0 & 67.8 & 68.2 & 67.9 & 67.8 \\
\hline Available UTS records in GPRD (y) & 7971 & 32260 & 31657 & 65446 & 5071 & 21147 & 20933 & 41277 \\
\hline Follow up used in the analysis (y) & 1628 & 4505 & 4383 & 20511 & 987 & 3001 & 2860 & 12579 \\
\hline Total oesophageal cancer $(n=137)$ & 22 & 35 & 20 & 15 & 12 & 16 & 9 & 8 \\
\hline Already diagnosed at the start $(n=54)$ & 4 & 21 & 7 & 3 & 1 & 9 & 5 & 4 \\
\hline Within first year of follow up $(n=45)$ & 9 & 9 & 9 & 4 & 7 & 4 & 2 & 1 \\
\hline Beyond first year of follow up $(n=38)$ & 9 & 5 & 4 & 8 & 4 & 3 & 2 & 3 \\
\hline Having endoscopy record & $62 \%$ & $36 \%$ & $22 \%$ & $7 \%$ & $59 \%$ & $36 \%$ & $22 \%$ & $8 \%$ \\
\hline \multicolumn{9}{|l|}{ Smoking } \\
\hline Never or non-smoker & $48 \%$ & $48 \%$ & $50 \%$ & $44 \%$ & $64 \%$ & $62 \%$ & $63 \%$ & $59 \%$ \\
\hline Ex-smoker & $16 \%$ & $15 \%$ & $14 \%$ & $12 \%$ & $9 \%$ & $9 \%$ & $9 \%$ & $8 \%$ \\
\hline Current smoker & $17 \%$ & $20 \%$ & $20 \%$ & $16 \%$ & $9 \%$ & $12 \%$ & $12 \%$ & $10 \%$ \\
\hline Missing & $19 \%$ & $18 \%$ & $17 \%$ & $28 \%$ & $17 \%$ & $18 \%$ & $16 \%$ & $24 \%$ \\
\hline \multicolumn{9}{|l|}{ Alcohol } \\
\hline Non-drinkers & $11 \%$ & $9 \%$ & $10 \%$ & $8 \%$ & $21 \%$ & $19 \%$ & $20 \%$ & $16 \%$ \\
\hline Infrequent drinkers (rarely or occasionally) & $14 \%$ & $17 \%$ & $17 \%$ & $14 \%$ & $23 \%$ & $24 \%$ & $24 \%$ & $22 \%$ \\
\hline Regular drinkers & $17 \%$ & $17 \%$ & $17 \%$ & $14 \%$ & $8 \%$ & $10 \%$ & $9 \%$ & $10 \%$ \\
\hline Missing & $58 \%$ & $56 \%$ & $56 \%$ & $64 \%$ & $49 \%$ & $47 \%$ & $47 \%$ & $51 \%$ \\
\hline \multicolumn{9}{|l|}{ Body mass index } \\
\hline Normal weight (18-24) & $29 \%$ & $30 \%$ & $30 \%$ & $27 \%$ & $28 \%$ & $32 \%$ & $32 \%$ & $33 \%$ \\
\hline Overweight (25-29) & $37 \%$ & $37 \%$ & $38 \%$ & $31 \%$ & $31 \%$ & $29 \%$ & $30 \%$ & $25 \%$ \\
\hline Obese $(>30)$ & $10 \%$ & $11 \%$ & $11 \%$ & $10 \%$ & $17 \%$ & $15 \%$ & $15 \%$ & $12 \%$ \\
\hline Missing & $24 \%$ & $22 \%$ & $21 \%$ & $31 \%$ & $25 \%$ & $24 \%$ & $23 \%$ & $29 \%$ \\
\hline
\end{tabular}

having Barrett's oesophagus (that is, to represent the general population). Subjects in the oesophagitis, simple reflux, and standard reference cohorts were $4 / 1,4 / 1$, and $8 / 1$, respectively, matched to each Barrett's case by age, sex, and general practitioner practice, and were alive and contributing data at the date of the first diagnosis of Barrett's oesophagus in their matched Barrett's case (the index date).

We defined the start and end date of the follow up periods for the study subjects within the available up to standard GPRD records. The start date of the follow up period was defined for each individual as the first diagnosis of Barrett's in the Barrett's cohort (the index date), the first diagnosis of oesophagitis or the index date whichever was the latest in the oesophagitis cohort, the first diagnosis of reflux or the index date whichever was the latest in the reflux cohort, and the index date in the standard reference cohort. Follow up ended at the end of the available up to standard GPRD records. Age at the beginning of the follow up period was used for the analysis which was grouped in 10 year categories. All oesophageal cancers that occurred before the start or in the first year of the follow up period in the Barrett's, oesophagitis, and reflux cohorts were regarded as prevalent cases and excluded from the analyses. (Symptoms of oesophageal cancer might have led these subjects to seek medical attention. Hence any oesophageal cancer diagnosed in these subjects shortly after the start of the relevant follow up period would have been prevalent at the time of the start of this period.) For the standard reference cohort, only oesophageal cancer cases occurring before the start of the follow up were regarded as prevalent.

We used Cox's proportional hazards regression analysis to estimate the hazard ratios and their 95\% confidence intervals (CI). The proportional hazards assumption was checked by plotting log cumulative hazard plots. The analysis was repeated for men and women separately and the interaction between sex and study cohort was explored. Information on a number of possible confounding factors, including smoking, alcohol consumption, and body mass index was extracted and their possible confounding effects were explored while using a separate category for missing values. Restriction analysis was performed selecting those subjects in the Barrett's, oesophagitis, and reflux cohorts having a record of endoscopy in their available GPRD records and their corresponding matched standard reference cohort. SPSS 11, Stata 7 (Stata Corporation, Texas, USA), confidence interval analysis (CIA), and Microsoft Excel 97 programs were used for analysis.

As histology was not available for the majority of oesophageal cancer cases, the relative risk of oesophageal adenocarcinoma in study cohorts could not be calculated directly by the Cox method and therefore was estimated using the standardised incidence ratio (SIR) method. Incidence rates were calculated by dividing the number of oesophageal cancers by the person years of follow up, and 95\% CI were calculated based on the Poisson distribution. In order to estimate the number of "observed oesophageal adenocarcinomas" in each cohort, we made the assumption that the incidence of squamous and other non-adenocarcinoma oesophageal cancers would be the same in each study cohort regardless of the presence of Barrett's or oesophagitis. For this purpose, firstly the expected numbers of nonadenocarcinoma cancers were calculated using the population age and sex specific incidence values for England and Wales between 1988 and 1993 and were corrected in the Barrett's, oesophagitis, and reflux cohorts using the formula: expected number of non-adenocarcinoma $\times$ observed/ expected numbers of oesophageal cancers in the standard reference cohort. The correction was necessary because the number of observed oesophageal cancers in our standard reference cohort was slightly greater than the expected number calculated from the population incidence rates. Estimated numbers of "observed oesophageal adenocarcinomas" were found by subtracting the number of corrected expected non-adenocarcinoma cancers from all observed cases of oesophageal cancer in the cohorts. Using population incidence values in England and Wales between 1988 and 1993, the SIR and the ratio of each SIR (SIR ratio) compared with the standard reference cohort as well as their CI were calculated. The analysis was repeated for men and women. 


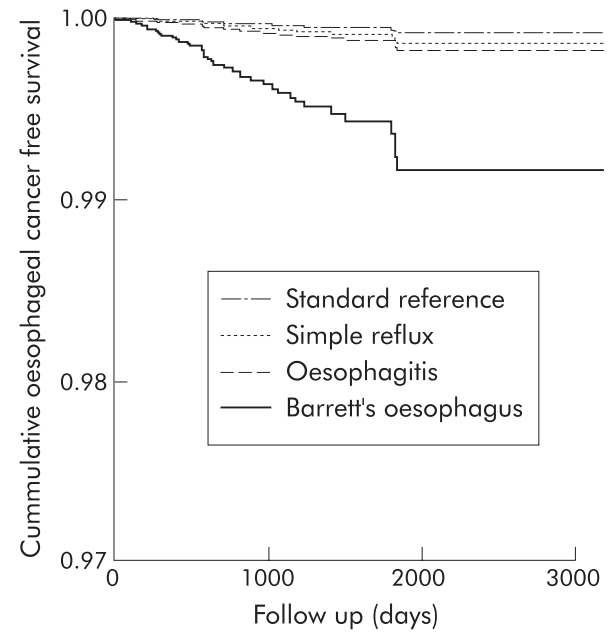

Figure 1 Predicted survival function in the study cohorts adjusted for age and sex.

\section{RESULTS}

Overall, there were 1677 subjects in the Barrett's cohort, 6392 in the oesophagitis cohort, 6328 in the reflux cohort, and 13416 in the standard reference cohort, making a total of 27813 subjects with, on average, eight years available GPRD records between 1987 and 2001. Characteristics of the study cohorts are summarised in table 1. Patients in the Barrett's oesophagus cohort were predominantly men (62\%) and the women were, on average, seven years older than men at the time of diagnosis of Barrett's. A total of 137 cases of oesophageal cancer were identified in the available GPRD records of the study subjects. Of these, 54 had already been diagnosed at the start of follow up and 40 more cases were diagnosed in the first year of follow up in the Barrett's, oesophagitis, and reflux cohorts and were excluded from the analysis as being prevalent cases. The remaining 43 incident oesophageal cancers were used in the final analysis. The absolute risk (crude incidence rate) was estimated in Barrett's oesophagus cohort using the number of incident cancers and the person years of follow up (table 1). The absolute risk for oesophageal cancer was 1 in 201 person years in men and women altogether. This value was 1 in 181 for men and 1 in 247 for women.

The hazard ratios for developing oesophageal cancer compared with the standard reference cohort were 10.6 (95\% CI 5.1-22.0) for the Barrett's cohort, 2.2 (95\% CI 0.95.2 ) for the oesophagitis cohort, and 1.7 (95\% CI 0.7-4.5) for the simple reflux cohort (table 2, fig 1). The relative risks were similar in men and women, with no significant interaction being detected between study cohorts and sex. No substantial confounding effects were detected for smoking, alcohol, and body mass index in multivariate analysis. Repeating the analysis for those subjects in the Barrett's, oesophagitis, and reflux cohorts who also had a record of endoscopy in their available GPRD records and their corresponding matched subjects from the standard reference cohort, increased the relative risk estimates for the Barrett's cohort to 22.1 (95\% CI 8.7-56.6) but left the relative rate for the oesophagitis and reflux cohorts relatively unchanged $(2.8$ (95\% CI 1.0-7.7) and 1.1 (95\% CI 0.1-8.3), respectively).

The relative risks of oesophageal cancer estimated by the SIR method were similar to those estimated by Cox regression, and the estimates for men and women were virtually the same (table 3). Using the SIR method, the risk of oesophageal adenocarcinoma was estimated to be 29.8 (95\% CI 9.6-106), 4.5 (95\% CI 1.04-19.6), and 3.1 (95\% CI 0.614.2) in the Barrett's, oesophagitis, and simple reflux cohorts compared with the standard reference cohort, respectively.

\section{DISCUSSION}

Our study shows that the risk of oesophageal cancer is increased by approximately 10-fold in patients with Barrett's oesophagus compared with the general population. The increase in risk is substantially lower in oesophagitis and simple reflux (approximately 2-3 fold in both cohorts). Estimation of the risk of oesophageal adenocarcinoma yielded higher values of relative risk of approximately 30 , 4.5, and 3 for Barrett's, oesophagitis, and reflux cohorts, respectively. Although we had only limited power to examine the differences in risk for men and women with Barrett's, our findings suggest that their crude risks for oesophageal cancer are not dissimilar.

The data collected within the GPRD is audited so as to ensure that at least $95 \%$ of all morbidity and prescribing information is recorded. Nevertheless, it is possible that some conditions may be under recorded and that some degree of misclassification could be present in the study cohorts. The lower percentages of records with endoscopy recorded in the oesophagitis and reflux cohorts compared with the Barrett's cohort suggests that it is more likely that these cohorts will contain some misclassified cases of Barrett's oesophagus resulting in overestimation of the cancer risk in these groups, which will have a conservative effect on the conclusions drawn in this study. However, we believe that Barrett's oesophagus is a diagnosis unlikely to be used by general practitioners without endoscopic and/or histological confirmation. We would expect therefore a level of validity for Barrett's similar to inflammatory bowel disease, which has been shown to be a highly valid diagnosis within the GPRD. ${ }^{31}$ When we performed a restriction analysis on only those individuals with a record of endoscopy, we found risk estimates of 22.1 (8.7-56.6), 2.8 (1.0-7.7), and 1.1 (0.1-8.3) for the Barrett's, oesophagitis, and reflux cohorts, respectively. The increase in the risk estimates in the Barrett's cohort and the minimal changes in the oesophagitis/simple reflux cohorts supports the assumed effect of possible misclassification. Indeed, we might expect those subjects with at least one endoscopy record in their GPRD record to represent a more severe subgroup of cases, so it is

Table 2 Hazard ratios (HR) and 95\% confidence intervals (Cl) of oesophageal cancer in the study cohorts adjusted for age and sex

\begin{tabular}{|c|c|c|c|c|c|c|}
\hline \multirow[b]{2}{*}{ Cohorts } & \multicolumn{2}{|l|}{ All } & \multicolumn{2}{|l|}{ Men } & \multicolumn{2}{|c|}{ Women } \\
\hline & Cancer* & HR $(95 \%$ Cl) & Cancer & HR $(95 \%$ Cl) & Cancer & HR $(95 \%$ Cl) \\
\hline Barrett's & 13 & $10.6(5.1-22.0)$ & 9 & $9.9(4.2-23.5)$ & 4 & $12.6(3.2-50.5)$ \\
\hline Oesophagitis & 8 & $2.2(0.9-5.2)$ & 5 & $1.9(0.7-5.4)$ & 3 & $3.3(0.7-14.9)$ \\
\hline Simple reflux & 6 & $1.7(0.7-4.5)$ & 4 & $1.6(0.5-4.9)$ & 2 & $2.4(0.4-13.4)$ \\
\hline Standard ref & 16 & 1.00 & 12 & 1.00 & 4 & 1.00 \\
\hline
\end{tabular}


Table 3 Standardised incidence ratios (SIR) and 95\% confidence intervals (CI) of oesophageal cancer and estimation of oesophageal adenocarcinoma in the study cohorts

\begin{tabular}{|c|c|c|c|c|c|c|c|c|c|c|}
\hline & \multicolumn{4}{|c|}{ Oesophageal cancer } & \multicolumn{6}{|c|}{ Estimation for oesophageal adenocarcinoma } \\
\hline & $\begin{array}{l}\text { Obs } \\
\text { OC }\end{array}$ & $\begin{array}{l}\text { Exp } \\
\text { OC }\end{array}$ & $\begin{array}{l}\text { SIR } \\
(95 \% \text { CI) }\end{array}$ & $\begin{array}{l}\text { SIR ratio } \\
(95 \% \text { CI) }\end{array}$ & $\begin{array}{l}\text { Exp } \\
\text { non- } \\
\text { OAC }\end{array}$ & $\begin{array}{l}\text { Exp* } \\
\text { non- } \\
\text { OAC }\end{array}$ & $\begin{array}{l}\text { Est } \\
\text { Obs } \\
\text { OAC }\end{array}$ & $\begin{array}{l}\text { Exp } \\
\text { OAC }\end{array}$ & $\begin{array}{l}\text { SIR } \\
(95 \% \text { CI) }\end{array}$ & $\begin{array}{l}\text { SIR ratio } \\
(95 \% \mathrm{CII})\end{array}$ \\
\hline \multicolumn{11}{|c|}{ All men and women ( 43 cancers) } \\
\hline Barrett's & 13 & 1.0 & $13(7-22.2)$ & $9.8(4.3-21.6)$ & 0.65 & 0.87 & 12.13 & 0.31 & $39.1(20.2-68.3)$ & $29.8(9.6-106)$ \\
\hline Oesophagitis & 8 & 2.8 & $2.9(1.2-5.6)$ & $2.1(0.8-5.3)$ & 1.95 & 2.6 & 5.4 & 0.9 & $6.0(1.9-14)$ & $4.5(1.0-19.6)$ \\
\hline Reflux & 6 & 2.7 & $2.2(0.8-4.8)$ & $1.7(0.5-4.5)$ & 1.87 & 2.49 & 3.51 & 0.86 & $4.1(1.1-10.5)$ & $3.1(0.6-14.2)$ \\
\hline Standard ref & 16 & 12.0 & $1.3(0.8-2.2)$ & 1.00 & 8.16 & 10.88 & 5.12 & 3.84 & $1.3(0.4-3.1)$ & 1.00 \\
\hline \multicolumn{11}{|c|}{ Men (30 cancers) } \\
\hline Barrett's & 9 & 0.6 & $15(6.9-28.5)$ & $10.3(3.8-26.5)$ & 0.4 & 0.59 & 8.41 & 0.25 & $33.6(14.5-66.3)$ & $23.2(6.6-89)$ \\
\hline Oesophagitis & 5 & 1.9 & $2.6(0.9-6.1)$ & $1.8(0.5-5.5)$ & 1.16 & 1.7 & 3.3 & 0.71 & $4.6(1-13.6)$ & $3.2(0.5-16.3)$ \\
\hline Reflux & 4 & 1.8 & $2.2(0.6-5.7)$ & $1.5(0.4-5)$ & 1.12 & 1.64 & 2.36 & 0.68 & $3.5(0.4-12.5)$ & $2.4(0.2-14.4)$ \\
\hline Standard ref & 12 & 8.2 & $1.5(0.8-2.6)$ & 1.00 & 5.07 & 7.45 & 4.55 & 3.1 & $1.5(0.5-3.4)$ & 1.00 \\
\hline \multicolumn{11}{|c|}{ Women (13 cancers) } \\
\hline Barrett's & 4 & 0.3 & $13.3(3.6-34.1)$ & $12.7(2.4-68)$ & 0.25 & 0.26 & 3.74 & 0.06 & $62.3(22-130.6)$ & $60.3(5.9-2949)$ \\
\hline Oesophagitis & 3 & 1.0 & $3(0.6-8.8)$ & $2.9(0.4-16.8)$ & 0.79 & 0.83 & 2.17 & 0.19 & $11.4(1.4-41.3)$ & $10.9(0.6-648)$ \\
\hline Reflux & 2 & 0.9 & $2.2(0.3-8)$ & $2.1(0.2-14.7)$ & 0.75 & 0.78 & 1.22 & 0.18 & $6.8(0.2-37.8)$ & $6.5(0.08-511)$ \\
\hline Standard ref & 4 & 3.8 & $1.1(0.3-2.7)$ & 1.00 & 3.09 & 3.23 & 0.77 & 0.74 & $1.0(0.03-5.8)$ & 1.00 \\
\hline
\end{tabular}

unsurprising that by restricting in this way we found a doubling of the risk estimate in the Barrett's cohort. Although only $61 \%$ of subjects in the Barrett's cohort had a record of endoscopy in their available follow up periods, it should be appreciated that lack of a record of endoscopic examination does not necessarily indicate lack of endoscopy. It is possible for the result of or diagnosis made at an endoscopy to be recorded without also recording that endoscopy had been performed.

Our estimate of the adenocarcinoma risk (SIR) was based on two assumptions. Firstly, that Barrett's or oesophagitis has little effect on the risk of non-adenocarcinoma cancer and secondly, that the proportion of oesophageal cancer without histological confirmation is small. Indeed, data from the Office of National Statistics ${ }^{32}$ shows that the proportion of cancers without histological confirmation during the period we used for our reference rates was less than $0.5 \%$.

Our study included 1677 people with Barrett's oesophagus who contributed more than 2600 person years at risk selected from the general population of the UK. The only larger cohort study of oesophageal cancer in Barrett's, recently published from Northern Ireland, ${ }^{33}$ found an incidence of oesophageal adenocarcinoma of $4 / 1000$ person years, which is similar to our estimate of 5/1000 for all oesophageal cancers. Although we were unable to adjust for socioeconomic status, our cohorts were closely matched for age, sex, and community to minimise the effect of confounding by these and other related variables. We were also able to examine the effect of smoking, alcohol, and body mass index on risk estimates. Notwithstanding the presence of some missing data for these variables, in the event we found no evidence of confounding by these factors. In addition, our study included cohorts of patients with oesophagitis and reflux alone, allowing a better understanding of the actual risk of oesophageal cancer in these groups than has previously been possible.

Our finding of a large difference between the relative risk estimates for developing oesophageal cancer and adenocarcinoma of the oesophagus in the Barrett's cohort (approximately 10 and 30, respectively) in comparison with the oesophagitis and simple reflux cohorts (approximately 2-3 and 3-4.5, respectively) is of particular interest. This contrasts with the argument made by some researchers that oesophageal reflux per se could play a major role in the development of oesophageal adenocarcinoma. ${ }^{29}{ }^{34} 35$ The large difference between the risk estimates for the Barrett's cohort compared with those for the oesophagitis and reflux cohorts indicates the importance of Barrett's oesophagus in these patients. The much lower risk of oesophageal cancer in simple reflux and even oesophagitis supports the idea that development of Barrett is an important step in the neoplastic transformation of lower oesophageal epithelium exposed to the carcinogenic gastric reflux. ${ }^{6}{ }^{36}$

The similarity of relative and absolute risk of oesophageal cancer in men and women with Barrett's oesophagus is also of importance. While the age adjusted incidence of oesophageal adenocarcinoma in women is approximately a third of that in men in several countries, including the UK, ${ }^{37-42}$ our results suggest that in patients with Barrett's the crude incidence rate in men and women is not so different. While this is a reflection of the seven year sex difference in age at diagnosis of Barrett's oesophagus, it does suggest that the clinical approach towards men and women diagnosed with Barrett's should be the same.

In summary, our study showed that Barrett's oesophagus increased the risk of oesophageal cancer by approximately 10-fold and oesophageal adenocarcinoma by approximately 30 -fold in comparison with the general population. The risk was similar in men and women, indicating that once men or women develop Barrett's oesophagus they are at a similar risk of developing oesophageal adenocarcinoma. There was only a modest increase in the risk of oesophageal cancer in patients diagnosed with oesophagitis or uncomplicated reflux without having Barrett's oesophagus. The important practical implication of these findings is that diagnosis of Barrett's oesophagus should remain a major turning point in managing patients with gastro-oesophageal reflux with regard to their risk of developing oesophageal adenocarcinoma.

\section{ACKNOWLEDGEMENTS}

This study was made possible by a grant from Special Trustees for Nottingham University Hospitals.

\footnotetext{
Authors' affiliations

M Solaymani-Dodaran, R F A Logan, J West, T Card, University of Nottingham, Division of Epidemiology and Public Health, Medical School, Queen's Medical Centre, Nottingham, UK

C Coupland, University of Nottingham, Division of Primary Care, University Park, Nottingham, UK
} 


\section{REFERENCES}

1 Spechler SJ, Robbins AH, Rubins HB, et al. Adenocarcinoma and Barrett's esophagus. An overrated risk? Gastroenterology 1984;87:927-33.

2 Cameron AJ, OH BJ, Payne WS. The incidence of adenocarcinoma in columnar-lined (Barrett's) esophagus. N Engl J Med 1985;313:857-9.

3 Cooper BT, Barbezat GO. Barrett's oesophagus: a clinical study of 52 patients. Q J Med 1987:62:97-108

4 Achkar E, Carey W. The cost of surveillance for adenocarcinoma complicating Barrett's esophagus. Am J Gastroenterol 1988;83:291-4

5 Robertson CS, Mayberry JF, Nicholson DA, et al. Value of endoscopic surveillance in the detection of neoplastic change in Barrett's oesophagus. $\mathrm{Br} J$ Surg 1988;75:760-3.

6 Hameeteman W, Tytgat GN, Houthoff HJ, et al. Barrett's esophagus: development of dysplasia and adenocarcinoma. Gastroenterology 1989;9615 Pt 1):1249-56.

7 Ovaska J, Miettinen M, Kivilaakso E. Adenocarcinoma arising in Barrett's esophagus. Dig Dis Sci 1989;34:1336-9.

8 Miros M, Kerlin P, Walker N. Only patients with dysplasia progress to adenocarcinoma in Barrett's oesophagus. Gut 1991;32:1441-6.

9 Watson RGP, Porter KG, Sloan JM. Incidence of adenocarcinoma in Barrett's oesophagus and an evaluation of endoscopic surveillance. Eur J Gastroenterol Hepatol 1991;3:159-62

10 Williamson WA, Ellis FH jr, Gibb SP, et al. Barrett's esophagus. Prevalence and incidence of adenocarcinoma. Arch Intern Med 1991;151:2212-16.

11 Bartlesman JF, Hameeteman W, Tytgat GN. Barrett's oesophagus. Eur J Cancer Prev 1992;1:323-5.

12 Iftikhar SY, James PD, Steele RJ, et al. Length of Barrett's oesophagus: an important factor in the development of dysplasia and adenocarcinoma. Gut 1992;33:1155-8

13 Moghissi K, Sharpe DA, Pender D. Adenocarcinoma and Barrett's oesophagus. A clinico-pathological study. Eur J Cardiothorac Surg 1993;7:126-31.

14 McDonald ML, Trastek VF, Allen MS, et al. Barretts's esophagus: does an antireflux procedure reduce the need for endoscopic surveillance? J Thorac Cardiovasc Surg 1996;111:1135-8.

15 Ortiz A, Martinez de Haro LF, Parrilla P, et al. Conservative treatment versus antireflux surgery in Barrett's oesophagus: long-term results of a prospective study. Br J Surg 1996;83:274-8.

16 van der Burgh A, Dees J, Hop WC, et al. Oesophageal cancer is an uncommon cause of death in patients with Barrett's oesophagus. Gut 1996;39:5-8.

17 Wright TA, Gray MR, Morris Al, et al. Cost effectiveness of detecting Barrett's cancer. Gut 1996:39:574-9.

18 Drewitz DJ, Sampliner RE, Garewal HS. The incidence of adenocarcinoma in Barrett's esophagus: a prospective study of 170 patients followed 4.8 years. Am J Gastroenterol 1997;92:212-15.

19 Ferraris R, Bonelli L, Conio M, et al. Incidence of Barrett's adenocarcinoma in an Italian population: an endoscopic surveillance programme. Gruppo Operativo per lo Studio delle Precancerosi Esofagee (GOSPE). Eur J Gastroenterol Hepatol 1997;9:881-5.

20 Weston AP, Krmpotich PT, Cherian R, et al. Prospective long-term endoscopic and histological follow-up of short segment Barrett's esophagus: comparison with traditional long segment Barrett's esophagus. Am J Gastroenterol 1997:92:407-13.

21 Csendes A, Braghetto I, Burdiles P, et al. Long-term results of classic antireflux surgery in 152 patients with Barrett's esophagus: clinical, radiologic, endoscopic, manometric, and acid reflux test analysis before and late after operation. Surgery 1998;123:645-57.

22 Katz D, Rothstein R, Schned A, et al. The development of dysplasia and adenocarcinoma during endoscopic surveillance of Barrett's esophagus. Am J Gastroenterol 1998;93:536-41.

23 Streitz JM jr, Ellis FH jr, Tilden RL, et al. Endoscopic surveillance of Barrett's esophagus: a cost-effectiveness comparison with mammographic surveillance for breast cancer. Am J Gastroenterol 1998;93:911-15.

24 O'Connor JB, Falk GW, Richter JE. The incidence of adenocarcinoma and dysplasia in Barrett's esophagus: report on the Cleveland Clinic Barrett's Esophagus Registry. Am J Gastroenterol 1999;94:2037-42.

25 Weston AP, Badr AS, Hassanein RS. Prospective multivariate analysis of clinical, endoscopic, and histological factors predictive of the development of Barrett's multifocal high-grade dysplasia or adenocarcinoma. Am J Gastroenterol 1999;94:3413-19.

26 Eckardt VF, Kanzler G, Bernhard G. Life expectancy and cancer risk in patients with Barrett's esophagus: a prospective controlled investigation. Am J Med 2001;111:33-7.

27 Van der Veen AH, Dees J, Blankensteijn JD, et al. Adenocarcinoma in Barrett's oesophagus: an overrated risk. Gut 1989;30:14-18.

28 Shaheen NJ, Crosby MA, Bozymski EM, et al. Is there publication bias in the reporting of cancer risk in Barrett's esophagus? Gastroenterology 2000;119:333-8.

29 Lagergren J, Bergstrom R, Lindgren A, et al. Symptomatic gastroesophageal reflux as a risk factor for esophageal adenocarcinoma. N Engl J Med 1999;340:825-31.

30 Walley T, Mantgani A. The UK General Practice Research Database. Lancet 1997:350:1097-9.

31 Lewis JD, Brensinger C, Bilker WB, et al. Validity and completeness of the General Practice Research Database for studies of inflammatory bowel disease. Pharmacoepidemiol Drug Saf 2002;11:211-18.

32 ONS. Cancer. London: Office for National Statistics, 1998.

33 Murray L, Watson P, Johnston B, et al. Risk of adenocarcinoma in Barrett's oesophagus: population based study. BMJ 2003;327:534-5.

34 Johnston BT. The significance of heartburn. Q J Med, 2000;93:321-2.

35 Cohen S, Parkman HP. Heartburn-a serious symptom. N Engl J Med $1999 \cdot 340 \cdot 878-9$

36 Fass R, Hell RW, Garewal HS, et al. Correlation of oesophageal acid exposure with Barrett's oesophagus length. Gut 2001;48:310-13.

37 Armstrong RW, Borman B. Trends in incidence rates of adenocarcinoma of the oesophagus and gastric cardia in New Zealand, 1978-1992. Int J Epidemiol 1996;25:941-7

38 Botterweck AAM, Schouten $\sqcup$, Volovics A, et al. Trends in incidence of adenocarcinoma of the oesophagus and gastric cardia in ten European countries. Int J Epidemiol 2000;29:645-54.

39 Brewster DH, Fraser LA, McKinney PA, et al. Socioeconomic status and risk of adenocarcinoma of the oesophagus and cancer of the gastric cardia in Scotland. Br J Cancer 2000;83:387-90.

40 Hansson LE, Sparen P, Nyren O. Increasing incidence of both major histological types of esophageal carcinomas among men in Sweden. Int J Cancer 1993;54:402-7.

41 Hansen S, Wiig JN, Giercksky KE, et al. Esophageal and gastric carcinoma in Norway 1958-1992: incidence time trend variability according to morphological subtypes and organ subsites. Int J Cancer 1997:71:340-4.

42 Launoy G, Faivre J, Pienkowski P, et al. Changing pattern of oesophageal cancer incidence in France. Int J Epidemiol 1994;23:246-51. 